nutritional and exercise habits with emphasis on long term objectives rather than short term weight reduction.

We thank those who made helpful comments on an earlier draft of this paper, especially Professor J R T Colley.

\section{References}

1 Royal College of Physicians. Obesity. $\mathcal{J}$ R Coll Physicians Lond 1983;17:3-58.

2 Garrow JS. Indices of adiposity. Nutrition Abstracts and Reviews in Clinical Nutrition-Series A 1983;53:697-708

3 Hubert HB, Feinleib M, McNamara PM, Castelli WP. Obesity as an independent risk factor for cardiovascular disease: a 26 year follow-up of participants in the Framingham Heart Study. Circulation 1983;67:968-77.

4 Rabkin SW, Mathewson FAL, Hsu PH. Relation of body weight to development of ischaemic heart disease in a cohort of young North American men after a 26 year observation period: the Manitoba Study. Am $\mathcal{F}$ Cardiol 1977;39:452-8.

5 Rhoads GG, Kagan A. The relation of coronary disease, stroke and mortality to weight in youth and middle age. Lancet 1983;i:492-5.

6 Pett LB, Ogilvie GF. The report on Canadian average weights, heights and skinfolds. Canadian Bulletin of Nutrition 1957;5:1-81.

7 Abraham S, Johnson CL, Najjar MF. Weight by height and age for adults 18-74 years: United States, 1971-74. Hyattsville, Maryland: National Center for Health Statistics, 1979. (DHEW publication No (PHS) 79-1656 Vital and health statistics; series 11 ; No 208.)

8 Bjelke E. Variation in height and weight in the Norwegian population. British fournal of Preventive and Social Medicine 1971;25:192-202.

$9 \mathrm{Knight}$ I. The heights and weights of adults in Great Britain. London: HMSO, 1984. (Office of Population Censuses and Surveys, Social Survey Division.)

10 Mullins AG. The prognosis in juvenile obesity. Arch Dis Child 1958;33:307-14

11 Abraham S, Nordsieck M. Relationship of excess weight in children and adults. Public Health Rep 1960;75:263-73

12 Miller FJW, Billewicz WZ, Thomson AM. Growth from birth to adult life of 442 Newcastle-uponTyne children. British foumal of Preventive and Social Medicine 1972;26:224-30.

13 Charney E, Goodman HC, McBride M, Lyon B, Pratt R. Childhood antecedants of adult obesity. N Engl I Med 1976;295:6-9.

14 Zack PM, Harlan WR, Leaverton PE, Cornoni-Huntley J. A longitudinal study of body fatness in childhood and adolescence. Journal of Pediatrics 1979;95:126-30.

15 Garn SM, Lavelle M. Two decade follow up of fatness in early childhood. Am 7 Dis Child 1985;139:181-5.
16 Abraham S, Collins G, Nordsieck M. Relationship of childhood weight status to morbidity in adults. HSMHA Health Report 1971;86:273-84.

7 Hawk LJ, Brook CGD. Influence of body fatness in childhood on fatness in adult life. Br Med 7 1979;i:151-2.

18 Stark O, Atkins E, Wolff $\mathrm{OH}$, Douglas JWB. A longitudinal study of obesity in the National Survey of Health and Development. BrMed $\mathcal{F}$ 1981;283:13-7.

19 De Wijn JF. Vetzucht bii kinderen. Deel II: de mogelijke relatie van vetzucht op de kinderleeftijd met vetzucht op oudere leeftiid. $T$ Kindergeneesk 1981;49:208-13.

20 Atkins E, Cherry N, Douglas JWB, Kiernan KE, Wadsworth MEJ. The 1946 British birth cohort: an account of the origins, progress and results of the National Survey of Health and Development. In: Mednick SA, Baert AE, eds. Prospective longitudinal research; an empirical basis for the primary prevention of psychosocial disorders. Oxford: Oxford University Press, 1981:25-30.

21 Stewart AL. The reliability and validity of self reported weight and height. $\mathcal{J}$ Chronic Dis 1982;35:295-309.

22 Newens EM, Goldstein $\mathbf{H}$. Height, weight and the assessment of obesity in children. British Jourmal of Preventive and Social Medicine 1972;26:33-9.

23 Cole TJ. A method for assessing age-standardized weight-for-height in children seen crosssectionally. Ann Hum Biol 1979;6:249-68.

24 Ashwell M, Cole TJ, Dixon AK. Obesity: a new insight into the anthropometric classification of fat distribution shown by computed tomography. $\mathrm{BrMed} \mathcal{F}$ 1985;290:1692-4.

25 Durnin JVGN, Womersley J. Body fat assessed from total body density and its estimation from skinfold thickness measurements on 481 men and women aged $16-72$ years. $\mathrm{Br} \mathcal{J}$ Nutr 1974;32:77-97.

26 Bray GA, ed. Obesity in America. Proceedings of the 2nd Fogarty International Centre conference on obesity. Washington: DHEW, 1979:1-19.

27 Douglas JWB, Ross JM, Simpson HR. All Our Future. London: Peter Davies, 1968.

28 Crisp AH, Douglas JWB, Ross JM, Stonehill E. Some developmental aspects of disorders of weight. Joumal of Psychosocial Research 1970;14:313-20.

29 Rona RJ, Morris RW. National Study of Health and Growth: social and family factors and overweight in English and Scottish parents. Ann Hum Biol 1982;9: 147-56.

30 Peckham CS, Stark O, Simonite V, Wolff $\mathrm{OH}$. Prevalence of obesity in British children born in 1946 and 1958. BrMed F 1983;286:1237-41.

31 Wadsworth MEJ, Peckham CS, Taylor B. The role of national longitudinal studies in the prediction of health, development and behavior. In: Walker DB, Richmond JB, eds. Monitoring child health in the United States: selected issues and policies. Cambridge, Massachusetts: Harvard University Press, 1984:63-85.

32 Somerville SM, Rona RJ, Chinn S. Obesity and respiratory symptoms in primary school. Arch Dis Child 1984;59:940-4.

33 Peckham C, Stark O, Moynihan C. Obesity in school children: Is there a case for screening? Public Health London 1985;99:3-9.

(Accepled 27 May 1986)

\title{
Influence of passive smoking on admissions for respiratory illness in early childhood
}

\author{
YUE CHEN, WANXIAN LI, SHUNZHANG YU
}

\begin{abstract}
An association was sought between passive smoking and inpatient admissions for respiratory illness in 1058 children born between 1 June and 31 December 1981 and living in the neighbourhoods of Nan-Jing Western Road and Yan-An Western Road in Jing-An District, Shanghai. The admission rate for first episodes of respiratory illness was positively correlated with the total daily cigarette consumption of family members during the children's first 18 months of life. The relative risk of developing a first episode of respiratory illness was 1.80 for children living in families including people who smoked 10 or more cigarettes a day compared with those living in non-smoking families. Multiple logistic regression analysis showed that the effect of passive smoking on inpatient admission for respiratory illness was independent of the child's birth weight, type of feeding, father's education, size of the home, and chronic respiratory disease among adults in the family. The adjusted odds ratios compared
\end{abstract}

\footnotetext{
Department of Epidemiology, School of Public Health, Shanghai Medical University, Shanghai 200032, People's Republic of China

YUE CHEN, MD, postgraduate student of public health

WANXIAN LI, MD, professor

SHUNZHANG YU, MD, professor

Correspondence to: Dr Yue Chen.
}

with the non-smoking group were $1 \cdot 17$ in families smoking 1-9 cigarettes daily and 1.89 in families smoking 10 or more cigarettes daily.

These data suggest that exposure to household cigarette smoke of children in early life increases the risk of severe respiratory illness.

\section{Introduction}

Cigarette smoking is one of the most important sources of air pollution in the home. ${ }^{12}$ As children in temperate zones are thought to spend most of their time indoors ${ }^{3}$ the potential hazards of indoor air pollution may be more important than those of outdoor air pollution. Many studies have reported that children exposed to parental cigarette smoking may have chronic cough, phlegm, and persistent wheeze and have higher risks of attacks of tonsillitis, pneumonia or bronchitis, and other respiratory illnesses. ${ }^{4-14}$ Harlap and Davies, in a prospective study of 10672 infants, found a dose response relation between the amount of maternal smoking and hospital admissions of infants for pneumonia and bronchitis. ${ }^{15}$ But it was argued that the mothers were reporting antenatal smoking instead of smoking during the first year of life, and paternal and other people's smoking was not considered. ${ }^{16}$ We present further evidence of an association between admission to hospital for respiratory illness and passive smoking in babies during the first 18 months of life without any maternal antenatal smoking effect. 


\section{Subjects and methods}

All 1163 babies born during 1 June to 31 December 1981 and living in the neighbourhoods of Nan-Jing Western Road and Yan-An Western Road in Jing-An District, in the centre of Shanghai, were selected for the study. Names, addresses, dates of birth, and the sex of the children were obtained from well baby clinics in the neighbourhood hospitals, which are notified of all births in the area as soon as they are certified. A self administered questionnaire was posted to each child's home to be completed by the parents or guardians when the child reached 18 months of age. This asked about dates and causes of inpatient admissions from birth to 18 months and smoking habits of parents and other family members. Other information included sociodemographic and educational state and living conditions of the family.

Of the 1163 parents or guardians sent the questionnaire, $674(58 \%)$ responded immediately and $330(28 \%)$ responded to postal reminders. Visits to the families' homes yielded a further 62 respondents, and the overall response rate was therefore $92 \%$. Data could not be obtained on 97 families, who either refused to participate or had moved and could not be traced. Names of children noted in the questionnaire as having a low birth weight (less than $2500 \mathrm{~g}$ ) were checked against the records of the Maternal and Child Health Care Institution of Jing-An District, where the babies had received special care, and the results showed complete consistency. There were no significant differences in sex, month of birth, or neighbourhood of residence at the time of birth between children in the respondent and non-respondent groups (table I). Among the respondents, three children diagnosed as having congenital heart disease and five who died early in the first 18 months of life were excluded, and the results are therefore based on the remaining 1058 children $(91 \%)$.

TABLE I - Sex, neighbourhood of residence, and month of birth of children among respondents and non-respondents

\begin{tabular}{lcc}
\hline & $\begin{array}{c}\text { No(\%) of respondents } \\
(\mathbf{n}=1066)\end{array}$ & $\begin{array}{c}\text { No(\%) of non-respondents } \\
(\mathbf{n}=97)\end{array}$ \\
\hline Boys & $554(52 \cdot 0)$ & $48(49 \cdot 5)$ \\
Girls & $512(48 \cdot 0)$ & $49(50 \cdot 5)$ \\
Neighbourhood of residence: & $712(66 \cdot 8)$ & $67(69 \cdot 1)$ \\
$\quad$ Nan-Jing Western Road & $354(33 \cdot 2)$ & $30(30 \cdot 9)$ \\
Yan-An Western Road & $90(8 \cdot 4)$ & $7(7 \cdot 2)$ \\
Birth month: & $123(11 \cdot 5)$ & $11(11 \cdot 3)$ \\
June & $147(13 \cdot 8)$ & $15(15 \cdot 5)$ \\
July & $160(15 \cdot 0)$ & $17(17 \cdot 5)$ \\
August & $188(17 \cdot 6)$ & $13(13 \cdot 4)$ \\
September & $176(16 \cdot 5)$ & $18(18 \cdot 6)$ \\
October & $182(17 \cdot 1)$ & $16(16 \cdot 5)$ \\
November & & \\
December & & \\
\hline
\end{tabular}

The reasons for admission to hospital during the first 18 months of life were divided into respiratory illnesses (ICD (9th revision) codes 460, 462-6, $472,485-7,490,491,493,786.1$ and 786.2$)^{17}$ and all other conditions.

An extension of the Mantel-Haenszel $\chi^{2}$ test $\left(\chi^{2}\right.$ M-EXT) was used to examine the linear trend of the inpatient admission rate. A multiple logistic regression model was used for multivariate analysis to examine the individual contribution of each passive smoking group on admission for respiratory illness after adjustment for potential covariates. In addition to passive smoking, the multiple logistic regression model included the following variables: baby's sex, method of feeding, birth weight, multiple birth, father's education, maternal age at birth, whether coal was used for cooking, average living area per person, family income, and whether there were any adult cases of chronic respiratory disease in the family; all were treated categorically.

The parameters of models were estimated by the method of maximum likelihood. Variables selected for the final model by a backward elimination procedure included smoking state of family members, which was of primary interest, and factors that potentially might confound the association between passive smoking and the admission rate for respiratory illness.

\section{Results}

Data on $998(94 \%)$ of the 1058 children were obtained from the postal questionnaire and on the remaining 60 by home visits. The main information from these two sources showed little variation (table II).

Overall $184(17 \cdot 4 \%)$ of the children were admitted to hospital at least once during their first 18 months of life, $100(9 \cdot 5 \%)$ for respiratory illnesses and 84
TABLE II-Comparison of data obtained from mailed answers and home visits

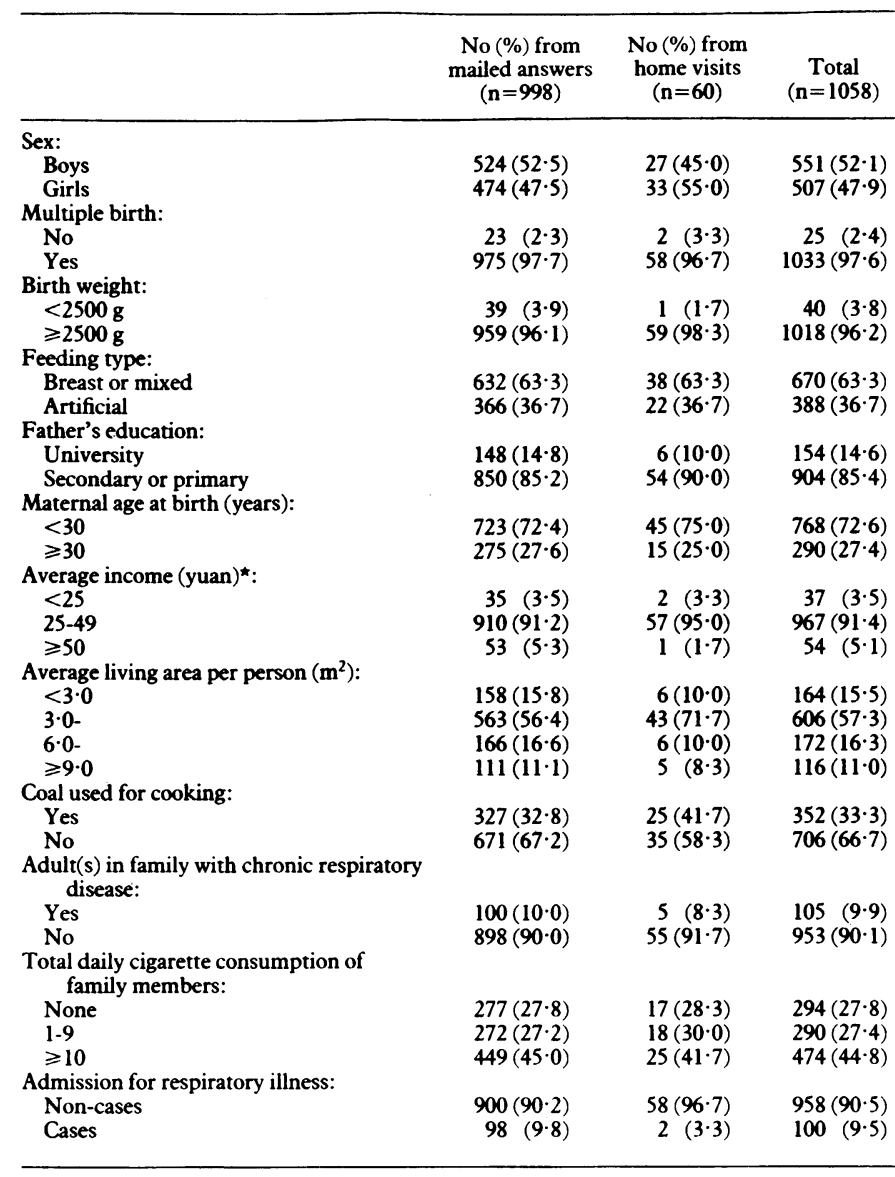

$\star_{1}$ Renminbi yuan $\approx 30$ p (early 1986 value).

$(7 \cdot 9 \%)$ for other conditions. Several children had been admitted twice or three times during this period.

A total of 764 children $(72 \cdot 2 \%)$ were living in families including smokers, and in 612 cases $(57 \cdot 8 \%)$ the father smoked. Exposure of the child to cigarette smoking was estimated from the total daily cigarette consumption of family members. Table III analyses admissions for first episodes of respiratory illness during the first 18 months of life in relation to the daily consumption of cigarettes by family members. The rate of admission increased with the number of cigarettes smoked daily $\left(\chi_{\mathrm{M}-\mathrm{EXT}}^{2}=2 \cdot 641\right.$; $\mathrm{p}<0.01)$.

TABLE III-Total daily cigarette consumption by family members and inpatient admissions of children for respiratory illness

\begin{tabular}{ccccc}
\hline Cigarettes smoked daily & Cases & Total children studied & Rate/100 & Relative risk \\
\hline None & 20 & 294 & $6 \cdot 80$ & $1 \cdot 00$ \\
$1-9$ & 22 & 290 & $7 \cdot 59$ & $1 \cdot 12$ \\
$\geqslant 10$ & 58 & 474 & $12 \cdot 24$ & $1 \cdot 80$ \\
\hline Total & 100 & 1058 & 9.45 & -
\end{tabular}

Smoking in families was closely associated with a lower educational state of the father (university educated, $84(54.5 \%)$ of 154 families; secondary or primary education only, $680(75 \cdot 2 \%)$ of 904 families $)$ and the presence of any adult with chronic respiratory diseases (case group $85 \cdot 7 \%$, non-case group $\mathbf{7 0} \cdot \mathbf{7} \%$ ). Children with low birth weights had a higher rate of admission for first episodes of respiratory illness $(7 / 40 ; 17 \cdot 5 \%)$ than children with normal birth weights $(93 / 1018 ; 9 \cdot 1 \%)$, though the difference was not statistically significant owing to the small number of low birth weight children. Artificial feeding was also an important predictor of admission for infectious diseases during the first 18 months of life (Chen et al, unpublished observations). After adjusting for each of these factors a significant linear trend in 
admissions for first episodes of respiratory illness in relation to total number of cigarettes smoked remained unchanged.

A multiple logistic regression model was used to compare the independent effect of exposure to household cigarette smoke on hospitalisation for respiratory illness from birth to 18 months after controlling for the effect of other variables. In addition to total daily smoking and number of family members, the adjusted variables in the final model included birth weight, type of feeding, father's education, average living area per person, and presence of any case of chronic respiratory illness in the family, which were selected by a backward elimination procedure. Table IV shows the odds ratios of admission for respiratory illness in the first 18 months of life unadjusted and adjusted for these covariates. The adjusted odds ratio for children of families smoking 10 or more cigarettes a day was significant compared with non-smoking families (odds ratio $1.89 ; p<0.05$ ). The adjusted odds ratio for children of families smoking 1-9 cigarettes a day was also more than unity compared with non-smoking families, but the difference was not significant (odds ratio $1 \cdot 17 ; p>0.05$ ).

TABLE IV-Unadjusted and adjusted odds ratio and 95\% confidence intervals for inpatient admissions for respiratory illness in early life in relation to total cigarette consumption by family members

\begin{tabular}{ccc}
\hline $\begin{array}{c}\text { Cigarettes } \\
\text { smoked daily }\end{array}$ & $\begin{array}{c}\text { Unadjusted odds ratio } \\
(95 \% \text { confidence interval })\end{array}$ & $\begin{array}{c}\text { Adjusted odds ratio } \\
(95 \% \text { confidence interval })\end{array}$ \\
\hline None & $1 \cdot 00$ & $1 \cdot 00$ \\
$1-9$ & $1 \cdot 12(0 \cdot 60-2 \cdot 10)$ & $1 \cdot 17(0 \cdot 60-2 \cdot 28)$ \\
$\geqslant 10$ & $1 \cdot 91(1 \cdot 12-3 \cdot 25)^{\star}$ & $1 \cdot 89(1 \cdot 06-3 \cdot 37)$
\end{tabular}

${ }^{\star} \mathrm{p}<0.05$.

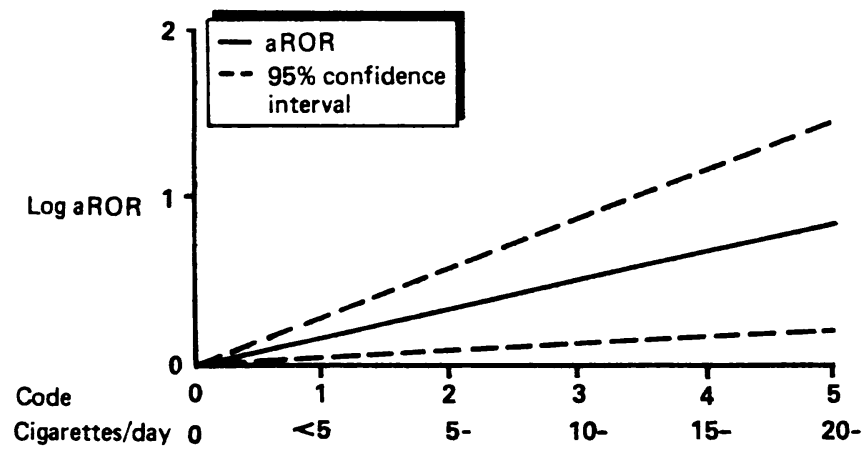

Dose response curve between patcrnal daily cigarette consumption and admission rate for respiratory illness in first 18 months of life. (aROR=Adjusted relative odds ratio.)

None of the mothers in the study smoked. We therefore analysed passive smoking in relation to the amount the father smoked and the amount other family members smoked. The adjusted odds ratios of admission for a first episode of respiratory illness during the first 18 months of life among children exposed to a total of 10 or more cigarettes daily by these members compared with non-smoking families were $1.83(\mathrm{Z}=2.205 ; \mathrm{p}<0.05), 95 \%$ confidence interval $1 \cdot 07-3 \cdot 14$, when the source was the father and 1.03 $(Z=0.127 ; p>0.05), 95 \%$ confidence interval $0.61-1 \cdot 75$, when the source was other family members. The figure shows the adjusted relative odds ratio of hospital admissions for respiratory illness as a function of the father's cigarette consumption.

There was no statistically significant association between passive smoking and admission to hospital for all other conditions during the first 18 months of life. The crude admission rates for first episodes were $9.0 \%$ for children in smoking families and $\mathbf{9 \cdot 5} \%$ for children in non-smoking families.

\section{Discussion}

This study shows a clear dose response relation between household exposure to cigarette smoke and the inpatient admission rate for first episodes of respiratory illness in the first 18 months of life. The findings support that of Harlap and Davies, who showed that infants of mothers who smoke have significantly more admissions for bronchitis or pneumonia. ${ }^{15}$
The increasing inpatient admission rate of these children with the consumption of cigarettes by family members reflected an increasing incidence of respiratory illness. This finding is consistent with many reports that children of parents who smoke have greater risks of various respiratory diseases and symptoms. ${ }^{+1+}$ Couples in China are encouraged to have only one child and to care for the health of that child very carefully. Admission to hospital is easily arrangedespecially in Shanghai, where medical care is better than in many other parts of China-and rates of admission are therefore a good indicator of the incidence of serious illness.

Though some studies have reported a significant association between parental smoking and an increased incidence of hospitalisation of children for respiratory diseases, they do not distinguish between the effect of passive exposure to cigarette smoke after birth and the effect of the mother's smoking during pregnancy..$^{1518}$ It has also been suggested that maternal smoking was associated with an increased proportion of low birthweight babies and higher risks of spontaneous abortion, fetal death, neonatal death, and complications of pregnancy. ${ }^{18}$ Though the adverse effects of exposure in utero cannot be ruled out in our study, smoking is very rare among young women in Shanghai and none of our mothers smoked; hence the possible adverse effects of maternal smoking during pregnancy were avoided and the harmful effects of household exposure to cigarette smoke on young children made clearer.

That the inpatient admission rate was closely associated with the fathers' smoking but not with the cigarette consumption of other family members is consistent with our earlier finding. ${ }^{19}$ The interpretation might be that children spend more time with their parents than with other family members. In addition, a self administered questionnaire usually completed by the parents might give inaccurate information on the smoking habits of other people. Requestioning about the daily cigarette consumption of 72 families selected at random after 6 months found a consistent rate of $87 \cdot 5 \%$ for other people compared with $95 \cdot 8 \%$ for the fathers (table V).

TABLE V-Daily cigarette consumption recorded initially and six months later on requestioning

\begin{tabular}{|c|c|c|c|c|c|c|c|c|}
\hline \multirow{3}{*}{$\begin{array}{c}\text { Cigarette } \\
\text { consumption on } \\
\text { requestioning }\end{array}$} & \multicolumn{8}{|c|}{ Cigarette consumption on initial questioning } \\
\hline & \multicolumn{4}{|c|}{ Fathers } & \multicolumn{4}{|c|}{ Other family members } \\
\hline & None & $1-9$ & $\geqslant 10$ & Total & None & $1-9$ & $\geqslant 10$ & Total \\
\hline $\begin{array}{l}\text { None } \\
1-9 \\
\geqslant 10\end{array}$ & 32 & $\begin{array}{r}1 \\
19 \\
1\end{array}$ & $\begin{array}{r}1 \\
18\end{array}$ & $\begin{array}{l}33 \\
20 \\
19\end{array}$ & 21 & $\begin{array}{r}2 \\
13 \\
4\end{array}$ & $\begin{array}{r}3 \\
29\end{array}$ & $\begin{array}{l}23 \\
16 \\
33\end{array}$ \\
\hline Total & 32 & 21 & 19 & 72 & 21 & 19 & 32 & 72 \\
\hline
\end{tabular}

Precise estimates of children's exposure to cigarette smoke are difficult to obtain because smokers might not smoke in the home, or the child might not be present while they are smoking, and so on. Nevertheless, it seems reasonable to assume that a child living in a household with a great deal of smoking will inhale large quantities of cigarette smoke.

Though a complete medical records system is not available, repeat data on 72 children were consistent with the earlier picture, 12 of them being admitted to hospital with the same diagnosis as before. This study supports our findings and adds further weight to the conclusion that adults' smoking may be detrimental to the health of their children.

We thank the staff of the well baby clinics in the neighbourhood hospitals of Nan-Jing Western Road and Yan-An Western Road for providing the names and addresses and other details of these children and helping in data collection.

\section{References}

1 Schmeltz I, Hoffmann D, Wyner EL. The influence of tobacco smoke on indoor atmospheres. Preo Med 1975;4:66-82. 
2 Stedman RL. The chemical comparison of tobacco and tobacco smoke. Chemical Reviews 1968;68:153-207.

3 Binder RE, Mitchell CA, Hosein HR, Bouhuys A. Importance of the indoor environment in air pollution exposure. Arch Environ Health 1976;31:277-9.

4 Lebowitz MD, Burrows B. Respiratory symptoms related to smoking habits of family adults. Chest 1976;69:48-50.

5 Colley JRT. Respiratory symptoms in children and parental smoking and phlegm production. $\mathrm{Br}$ Med f 1974;ii:201-4.

6 Bland M, Bewley BR, Pollard V, Banks MH. Effect of children's and parents' smoking on respiratory symptoms. Arch Dis Child 1978;53:100-5.

Weiss ST, Tager IB, Speizer FE, Rosner B. Persistent wheeze: its relationship to respiratory illness, cigarette smoking and level of pulmonary function in a population sample of children. Am Rev Respir Dis 1980;122:697-707.

8 Said G, Zalokar J, Lellouch J, Patois E. Parental smoking related to adenoidectomy and tonsillectomy in children. $f$ Epidemiol Community Health 1978;32:97-101.

9 Scholling RSF, Letai AD, Hui SL, Beck ST, Schoenberg JB, Bouhuys A. Lung function, respiratory disease, and smoking in families. Am f Epidemiol 1977;106:274-83.

10 Speizer FE, Ferris BJ, Bishop YMN, Spengler J. Respiratory disease rates and pulmonary function in children associated with $\mathrm{NO}_{2}$ exposure. Am Reo Respir $D$ is 1980;121:3-10.
11 Gortmacher SL, Walker DK, Jacobs RH, Ruch-Roiss H. Parental smoking and the risk of childhood asthma. Am $f$ Public Health 1982;72:574-9.

12 Pullan CR, Hey EN. Wheezing, asthma and pulmonary dysfunction 10 years after infection with respiratory syncytial virus in infancy. BrMed $\mathcal{F}$ 1982;284: 1665 -9.

13 Fergusson DM, Horwood LJ, Shannon FT, Taylor B. Parental smoking and lower respiratory illness in the first three years of life. 7 Epidemiol Community Health 1981;35: 180-4.

14 Colly JRT, Holland WW, Corkhill RT. Influence of passive smoking and parental phlegm on pneumonia and bronchitis in early childhood. Lancet 1974; ii: 1031 -4

5 Harlap S, Davies AM. Infant admissions to hospital and maternal smoking. Lancet 1974; ; :529-32. 16 Weiss ST, Tager IB, Schenker M, Speizer FE. The health effects of involuntary smoking. Am Re Respir Dis 1983;5:933-42

7 World Health Organisation. International classification of diseases. 9th revision, 1975 Vol 1. Geneva: WHO, 1977

18 US Department of Health and Human Services. The health consequences of smoking for women: report of the Surgeon General. Washington: US Government Printing Office, 1980.

19 Yue Chen, Wanxian Li. The effect of passive smoking on children's pulmonary function in Shanghai. Am 7 Public Health 1986;76:515-8.

(Accepted 7 April 1986)

\title{
Plasma cholesterol concentration and death from coronary heart disease: 10 year results of the Whitehall study
}

\author{
GEOFFREY ROSE, MARTIN SHIPLEY
}

\begin{abstract}
Ten year mortality from coronary heart disease in $\mathbf{1 7} \mathbf{7 1 8}$ middle aged men was related to their initial plasma cholesterol concentrations. The relative risk of death from coronary heart disease declined with age, but the absolute excess risk did not. The risk gradient was continuous over the whole range of cholesterol concentrations, the lowest mortality being among men with concentrations below the lowest decile. It seems that, as with blood pressure, the average cholesterol concentration in the population is too high: lowest concentrations are prognostically the best. A quarter of all deaths from coronary heart disease related to cholesterol occurred among men with concentrations above the top decile, but $55 \%$ occurred among men with concentrations in the middle three fifths of the distribution; this figure of $55 \%$ could be reduced only by a policy aimed at lowering concentrations in the whole population.
\end{abstract}

\section{Introduction}

The association between high blood cholesterol concentrations and a person's risk of coronary heart disease is now widely accepted. The relation at lower concentrations has been harder to assess, because the shallower gradient and lower incidence call for exceptionally large studies. The question is, however, of great importance in terms of the possible benefits of dietary advice to the population. In the Whitehall study plasma cholesterol concentration was measured in a large group of men whose mortality has now been followed up for over 10 years; this provided enough data for us to explore this question.

\section{Methods}

Data were available on 17718 male civil servants aged 40-64 in London. ${ }^{12}$ Plasma cholesterol concentration at entry to the study was measured on a capillary blood sample, using the then standard Technicon method N24a; it is now suspected that the readings may have been about $10 \%$ too low, and so the results are presented here within deciles or quintiles. The quintile points (uncorrected) were $4 \cdot 11,4 \cdot 75,5 \cdot 27$, and $6.05 \mathrm{mmol} / \mathrm{l}(159,184,204$, and 234 $\mathrm{mg} / 100 \mathrm{ml}$ ). Concentrations were not significantly related to age. Recording of deaths was virtually complete owing to the help of the National Health Service Central Registry. During the first 10 years 703 men died of coronary heart disease (International Classification of Diseases (eighth revision) codes 410-414)

\section{Results}

Table I shows mortality from coronary heart disease at 10 years within deciles and quintiles of plasma cholesterol concentration. There was a clear and highly significant trend over the whole range of concentrations, some small irregularities being well within sampling limits. The slope of the fitted linear regression corresponded to a change of 0.64 deaths from coronary heart disease $/ 100 \mathrm{men} / 10$ years for a change in cholesterol concentration of $1 \mathrm{mmol}(38.7 \mathrm{mg})$, with no significant departure from a linear trend. An optimal lower concentration could not be established: within the range observed the lower the concentration the better, as mortality associated with concentrations in the lowest tenth of the distribution was $9 \%$ lower than that associated with concentrations in the next lowest tenth.

If the mortality among all the men had been the same as that among the men whose concentrations were below the lowest decile then 482 rather than 703 deaths from coronary heart disease would have been expected, a reduction of $221(31 \%)$. This underestimates the true proportion of deaths from coronary heart disease attributable to cholesterol for two reasons. Firstly, it was not possible to establish the optimum plasma cholesterol concentration, relative to which the excess of deaths from coronary heart disease related to cholesterol could be measured, as the real "minimum risk" category seemed to be below that of the lowest tenth in the study. Secondly, as the cholesterol concentration was measured only once gradients at both extremes would have been underestimated because of the effects of random error and regression to the mean.

The final columns of table I show the best estimates of the distribution of the deaths attributable to cholesterol. Such deaths were spread over the whole range of cholesterol concentrations, with $55 \%$ arising in the middle of the distribution (between the first and fourth quintiles). Roughly one quarter were associated with concentrations above the top decile, and $43 \%$ with concentrations above the top quintile. The high proportion of attributable deaths at the top end of the distribution of concentrations was somewhat exaggerated because of the underestimate of total attributable 